\title{
Education for the Politics of "Voice": Cavell, Butler, and Acknowledging Others
}

\author{
Kazuma Sogabe*
}

\begin{abstract}
To address the modern political task of listening to the voices of excluded others, this paper will propose "the politics of voice" based on the thought of the American philosopher Stanley Cavell. It begins with a critique of Kelz's comparison, in political terms, between Cavell and Judith Butler. Butler's politics constantly challenges the norm by confronting its finitude and opening it to infinite possibilities so that the opinions that are currently invisible can be recognized. No matter how much existing knowledge is thus renewed, however, the actual understanding of others with this new knowledge will remain narcissistic unless one gets out of the objectifying construction of "Othering" in which "I know you." In contrast, Cavell teaches us another sphere of politics, where acknowledging others is indivisible from self-acknowledgment in that our "voices"-particular ways of inhabiting our everyday lives constituted by general knowledge-are simultaneously discovered in the form of finding out that they are absolutely different by accepting human epistemic finitude. After demonstrating the complementarity of Cavell's and Butler's politics through the example of slavery, I shall explore the prospects for political education from their respective ways of engaging with language.
\end{abstract}

Keywords: Stanley Cavell; Judith Butler; acknowledgment; politics of voice; language education

\section{Beyond the Construction of Othering}

In modern society, where cultures have become increasingly fluid, listening to the voices of excluded others is an urgent political task for realizing democracy. To address this problem, political education is required to not only provide knowledge of the society, but also

* Graduate student, Kyoto University; JSPS Research Fellow

e-mail: sogabe.kazuma.36c@st.kyoto-u.ac.jp 
foster a critical stance toward ourselves as members of that society.

Minority education is one such example. From the perspective of accepting those who are socially disadvantaged, the discourse has shifted from "assimilative education" to integrate minorities into the majority culture to "multicultural education" to reflect minorities' diverse cultures in the curriculum (Matsuoka 2000). However, this approach of promoting the majority's understanding of and respect for minorities can be insufficient. Kevin Kumashiro, an educationalist who proposes "antioppressive education," explicates this with his educational practice on sexual minorities.

In Troubling Education (2002), Kumashiro introduces his experience of having been referred to as "gay" by his students in the teacher education program, despite having explained his bisexuality earlier. According to his analysis, the future teachers placed him, one who was on the boundary of the gay-straight binary, on the "Other" side of it because such binarism is stable and comforting (1-4). This desire for stability conserves the social hierarchies that exclude beings such as bisexuals and even reproduces and reinforces them in the cycle of education (cf. 10-11). To change social structures, it is necessary not to tackle the problem as theirs in the form of "Othering" (23) wherein "we" know "them," but as ours by confronting our own complicity with oppression, despite the discomfort it causes, thereby "troubling," or destabilizing, the existing boundaries (1-4). Moreover, the antioppressive education that is thus realized can itself contribute to another oppression (9) since, as poststructuralism shows, humans are necessarily situated, contextualized, and partial beings (19-20). "Educators, therefore, have an ethical responsibility" (9) to constantly rethink their own practices (25).

Kumashiro's pedagogy of constant self-criticism can respond to the political task of hearing others" "voices" (19). To investigate the tenability of his teaching, this paper will first explore the philosophy of Judith Butler (1956-), one of the thinkers on whom he bases his theory in linguistic terms (50ff.). Yamaguchi (2016) discusses Butler's "political education." For Butler, while education is "a field in which subjects are constituted along the "norm," politics is "a field for challenging the "norm"”; therefore, her political education requires "the understanding that the field in which the 'norm' works is...regulated by 'power' but at the same time open to intervention" (212). Thus, "while conventional political education...can assume the existing 'norm' regarded as good or, by contrast, put too much confidence in the possibility of rearranging the 'norm' regarded as bad, Butler's thought does not miss the dynamic relationship between the 'norm' and subjects" (205). Accordingly, it is expected that Butler can convey the complexity of Kumashiro's ethical appeal for changing social structures. However, since Yamaguchi's focus is on connecting the two areas-politics and education - in Butler, her politics needs to be examined further.

The next section will review Kelz's theory of becoming a subject, where she juxtaposes Butler with an American philosopher, Stanley Cavell (1926-2018), and compares their views on language in political terms. Next, I shall object to this comparison by carefully analyzing Cavell's main theme of "acknowledging others." This will reveal Cavell's conception of "voice," in which our involvement when addressing the problem of knowing others takes place at a different level from Kumashiro's supposition and can go beyond the construction of Othering in the true sense. The goal of this paper is to set out the sphere of this way of being with others as Cavell's "politics of voice," which is complementary to Butlerian politics, and to open up the prospects for new political education. 


\section{Kelz's Linguistic Comparison between Butler and Cavell}

In The Non-Sovereign Self, Responsibility, and Otherness (2016), Rosine Kelz attempts to understand the recently disputed notion of human non-sovereignty and to explore its political significance. First, she refers to Heidegger's critique of the modern subject. Modern epistemology takes the human as the sovereign subject objectifying the external world. However, this artificial dividing of humans from their environment - or the construction of Otheringmisses the interconnection between them and is, therefore, insufficient to portray human existence. In contrast, Heideggerian ontology clarified the non-sovereign nature of humans as relational, situated, and finite. Yet Heidegger has been criticized for not following up on its importance because of his concern with solipsistic authenticity (4-7). Hence, Kelz restructures the notion of the non-sovereign self thoroughly, relying on the three leading American thinkers influenced by Heidegger: Hannah Arendt, Judith Butler, and Stanley Cavell. Whereas Arendt tends to divide public from private while providing the notion of the political, Butler and Cavell's attention to language makes it possible to think about the self's relational way of being "on the one hand closely connected to social norms, but on the other hand able to establish a critical distance to its social environment" (15-16). This question of a balance between communality and uniqueness registers a dynamic relationship, wherein subjects are not exclusively passive or active toward the norm-something that Yamaguchi finds in Butler's politics.

According to Kelz, Cavell rejects the sovereign view of language as a "mirror of the world," or one that describes the truth of an object (48); instead, drawing on Wittgenstein, he argues that the meaning of language is dependent on agreement with other speakers. Then, since speakers always use words in new, unexpected circumstances in the linguistic community, every speech act is a testing of the community in whether that use is accepted. This involves a risk of failure but also suggests the possibility of a personal contribution to creative change in concepts, which is necessary for the functioning of language (50-51). "Thus, agreement or communality on the one hand and unique selfhood or agency on the other stand in a productive tension with each other" (50). However, while the changeability of concepts has ethical importance, Kelz criticizes Cavell for overemphasizing voluntaristic agency, where speakers are depicted as "fully formed subjects" and the process of becoming members of a community is not considered (51-52). If a new interpretation of concepts relies on others' acceptance, it has to build on existing frameworks to maintain its intelligibility, so "creative change is not so much the adding of something entirely new but the rearrangement of the familiar," which limits the voluntaristic tendency (52). Kelz, then, turns to Butler's theory of becoming a subject.

Butler, like Cavell, thinks that linguistic signification changes through repetition (61); however, Kelz points out that there is a "difference in emphasis" between these two thinkers (62). Butler's close analysis of power structures reveals the way that becoming a subject necessitates first of all a subjection to the present social and linguistic norms (57). Therefore, unlike in Cavell, speakers are not equally competent to change concepts; rather, they are already interwoven with inequality upon appearing as recognizable subjects (63). ${ }^{1}$ Aware of this problem, Butler makes more of convention than intentionality (62) and, hence, validates a deconstructive strategy of undermining the power of norms from within. That is, since the meaning of a concept is, as structuralism showed, not defined by itself but established by its 
difference from other concepts in relation to "what it excludes," the subject's agency appears in repeating words in the way that exposes "their dependency and the impossibility of clear demarcation between...concepts," and dislocates the boundaries of concepts, taking advantage of their inherent ambiguity which is then laid bare, so that they will subsume the currently unrecognized lives (63-65). ${ }^{2}$ Thus, Butler gives us a more nuanced understanding of the notion of non-sovereignty (65).

In the empirical social world, however, we are always faced with competing demands. To decide between them, Butler suggests a "transition" (98) from the above ethical, non-sovereign politics of deconstructing norms to sovereign politics. Kelz resolves this either-or in the political sphere by introducing the notion of "the political" $(98-100) .^{3}$ That is, politics is

seen as the necessary codification of decisions that enable the existence of rights and lasting institutions. The ethical demand is the occasion where institutionali[z]ed politics and the sphere of rights are disrupted in the name of justice..., which would signify the appearance of the political where new forms of open political associations and action can develop.... This allows us to re-imagine the role of the political as a space where the forms of government, societal and economic structures, the subjects they produce, and the others they exclude can be critically interrogated. (163)

Making some decision, which is essential for putting politics into practice, necessarily excludes certain others under the sovereign construction of Othering. The political, then, reminds us every time of our non-sovereign way of being, and thereby current concepts turn out to be finite, are interrogated, and constantly re-created to be more egalitarian. Thus, Kelz envisages politics as a permanent critical project in which each of us can participate depending on how we use language.

\section{Finite Others, the Infinite Other, and Two Narcissisms}

I have so far outlined the politics that Kelz derives from the comparison between Butler's and Cavell's views on language. This section focuses on the issue of otherness there, taking into consideration this paper's task of hearing others' voices.

In knowing other minds, we refer to their behavior. Kelz (2016) understands that Cavell, in view of human epistemic finitude, insists that behavior be seen not only as an object of intellectual inquiry in terms of "knowledge," but as an address eliciting a response in terms of "acknowledging" (81). This responsibility is infinite because we cannot know all the consequences of communication (84), through which we learn how far we share linguistic community and where we separate from each other in the community, "“find a way out of isolation' again and again" (86-87) - this is inferred from the above discussion on linguistic changeability to indicate the re-creation of existing concepts - and come to acknowledge others. Kelz, however, criticizes Cavell for holding on to the finite other with the same status as the self, in spite of his attention to infinite responsibility. That is, because "he avoids the notion of an 'infinite' other, which he fears would eclipse the concrete other person," others appear merely limitedly knowable, not absolutely unknowable (89), so that responsibility takes place within intimate relationships and cannot deal with pressing political problems 
(85-86). In contrast, Butler allows for the infinite "Other," drawing on Levinas. ${ }^{5}$

In "the structure of knowledge" where "[a]ny form of knowledge is always established against what is precluded from it," the Other in Levinas represents this necessary "exclusion," that is, "what misses [sic] from the customary way of viewing the world" (95). Perceiving the manifestation of this infinite Otherness in (finite) others recalls the knowledge of the others being finite, which is then questioned anew; this relation of the Other to others corresponds to that of the political to politics. Levinas's Other is a "quasi-transcendental" (79) condition of possibilities in that it brings us back to the non-sovereignty of knowledge more fundamentally than in Cavell. A self is constituted by the Other in this sense, and the "violence" stemming from this predominance of the other over the self becomes a happy "trauma" as it unsettles the self's drive to sovereignty (ibid.). By contrast, the selves in Cavell, which appear as "already constituted subjects," are lacking in this perspective of constitutedness by others. Thus, Kelz flags the risk of falling into "moral narcissism" (85).

Cavell, however, addresses the very problem of narcissism in the paper on which Kelz relies: "What Is the Scandal of Skepticism?" (2005a). There, he develops a somewhat complicated discussion on the difference in otherness between himself and Levinas:

Where Levinas finds in Descartes's proof the opening to the finite other, I have been struck by the fact that these others - the existence of what Descartes there calls "men similar to myself" - are in that passage not revealed but instead passed by. Descartes specifically claims that, unlike the case of God,...the idea of a finite other creature is, by contrast, fully within the compass of such a creature's power to create. (145)

Levinas extracts the notion of the infinite Other from Descartes's proof for God's existence. However, to know others better, no matter how much existing knowledge is renewed through self-criticism in light of infinity, when I actually know others with this new knowledge-so long as I do not get out of the epistemological objectifying construction of Othering in which "I know you"- the understanding of the others will be "within the compass of" my own power. That is, the others who are thus known will continue to remain the self-projective "men similar to myself." The "narcissism" (ibid.) Cavell problematizes is this kind of limitation in knowing others, which is different from Kelz's. Cavell pays attention to the fact that such infinity is "passed by" in Descartes, and reads him as implying that there is another way of knowing others beyond the construction of Othering.

The assumption that the contrast between finitude and infinity can cover the entire structure of knowledge overlooks the problem of this narcissism. Cavell, therefore, dares to integrate this contrast into the notion of finitude on the grounds that it is still within the epistemological limitation and, thereby, sets aside the word "infinite" for another kind of transcendence of finitude:

Now when I say...this traumatic effect of the recognition of the existence of God is replaced by the idea of a finite other, violence and some sense of an infinite nevertheless remain. But in originating now in the face of a finite other, violence and infinitude cannot be thought to arise from a comparison of myself with the other but from a recognition that this particular other, this creature among all the creatures of the earth similar to me, is also, or rather therefore, absolutely different, separate from me, I would say, 
wholly other, endlessly other, the one I single out before whom I am I, eternally singled out. (145-146)

It is "achieving" separation of this particular other and I singled out in a dyadic relationship that leads me to escape from narcissistic isolation and, hence, "acknowledgment" of the other (146). This stands in contrast to Kelz's (2016) equation of "find[ing] a way out of isolation" with "break[ing] out of separation" (87).

Thus, Cavell's concern is with the problem that the permanent criticism of the norm through the political alone will overlook. Yet it does not follow that Cavell ignores political matters; his political view is expressed in the following:

Philosophy should be distinguished from argument, or political discourse.... When I distinguish philosophy from argument, I take argument most literally as taking one side of the division of friends and enemies in discussion.... If there is a conflict philosophically, we have not reached the bedrock of the problem troubling us.... This means if we are at odds with others, we are also at odds with ourselves and...we have to take the mind apart further. So, there is no position of friends and enemies in a philosophical solution. (Cavell 1998, 55) ${ }^{6}$

This is reinforced with a description: “[P]hilosophy's distinctive contribution to political argument...is to register whether our arguments with enemies are leveled within a realm that grants humanity to our enemies" (Cavell 2005b, 162). Here, another politics is suggested where-beyond the Othering construction of friends and enemies - acknowledging others as human beings is indivisible from self-acknowledgment reflexively.

It is reasonable for Kelz to point out that Cavell does not take into account the process of becoming a subject as Butler does, which confines responsibility within intimate community and lacks political urgency. Throughout her book, however, Kelz (2016) assumes the given vision of the non-sovereign self and, therefore, compares and evaluates Cavell and Butler (and Arendt) in terms of whether to fulfill the vision, as seen in her statement, "As a supplement to Cavell, I...turn to Butler's reading of Levinas" (79), without examining the significance of Cavell's image of the self itself. Similar logic can be found in this passage: "Stanley Cavell's work so far found little consideration in political theory. I argue, however, that his perspective can be used productively" (15), and Kelz indeed reproduces Cavell's thought so that it can be located in the politics she imagines. This deficiency in political studies on Cavell, however, should be regarded - by following his texts faithfully as aboveas an indication that he could present another politics based on his conception of acknowledgment. The next section, then, probes a way of acknowledging others that is indivisible from separation and reflexivity by unraveling Cavell's main work The Claim of Reason, whose Part IV investigates the problem of knowing other minds.

\section{Acknowledgment as Discovery of Our Own Voices}

The previous section has pointed out that in addressing the task of listening to others' voices, relying solely on Butler's politics advocating renewing of the norm-which can re- 
main within the epistemological construction of Othering-overlooks the problem of narcissism in that understanding others is self-projective. This section asks Cavell what it can be like to acknowledge others, hearing their voices beyond epistemology.

In The Claim of Reason (1979), Cavell elaborates the epistemological knowing of other minds as "the argument from analogy" $(393,478)$ : the other's body is like mine; therefore, as my body is connected with sentience, other bodies are connected with sentience. Here, the visible part of body represents the invisible mind, whose existence is inferred as "origins that no one can have been present at" (365). Body behavior is analyzed as accounting for the origin, and this knowledge will be renewed infinitely, never arriving at the true inner soul itself because of human finitude. In this process, however, I do not encounter the genuine other since the other is a being on which I project the existence of my mind. To save myself from this narcissistic isolation, I need to acknowledge the other person as such-as a human being. Accordingly, let us trace how Cavell regards humans, whose dual aspects will be revealed.

There can be various definitions of human beings. Here, Cavell considers a taxonomical one:

The idea we have of the human being is not, I assume, likely to be captured by a definition which specifies a genus. If we say that the human being is the rational animal, we have yet to specify the connection. (The philosophical usefulness of the genus homo is limited by the fact that all its species, with one exception, are extinct. If we had the others for comparison we might see what difference sapience makes and not wonder about the connection it must have with the body.) (398)

Human beings can be defined, for example, as rational animals, by the difference (= rational) in the likeness to other genera (= animal), in a structuralist way. This definition of human beings as animals is still epistemic in that it relies on the connection with other beings. Human beings, however, should have an aspect that cannot be captured by comparison with others, because species other than us, homo sapiens, are extinct. To approach human beings as human beings, therefore, we have no choice but to be "thrown back upon ourselves" (442). This implies a certain reflexivity in humanity, which is found in sayings such as, "If you do not treat him as human, your own humanity will be doubted" (cf. 493).

In this context, Cavell introduces the concepts of "authority" and "voice" (402-403) before developing a parable whose motif is a craftsman who, aiming to perfect automata, occasionally "force[d] me to look inside one of them to convince me that it was not a real human being" (403). A brief synopsis of Cavell's parable is as follows. -First, I was strolling in a garden with the craftsman and his automaton, and he cut off the automaton's clothes with a knife and showed its metal legs and leathery or rubbery hands. This may have convinced me that it was not human, but he still snapped off its brass chest to reveal clockwork inside. After years of improving the legs and hands, one day, when the craftsman snapped off the automaton's chest again, I felt "horror." There was no clockwork but the incomplete yet human insides (bones, digestive and circulatory systems, blood, etc.). Recoiling, I was hardly able to attend to his words: "The pain-responses are still mechanical. The issue is how to get the pain itself by simulating better responses." Time passed, and the craftsman reappeared with the perfected automaton. When he took out a knife, this time the automaton 
leaped up and started grappling with him, yelling, "No more. It hurts." Satisfied with my indecision about whether to intervene, he raised his arm and the automaton thereupon sat on a bench. Then I turned on the craftsman: "You've built in too much!"- namely a soul (403407).

It should be noted that the process of the automaton's perfect simulation of a human being triggered my horror. "Horror" is the title Cavell gives to

the perception of the precariousness of human identity, to the perception that it may be lost or invaded, that we may be, or may become, something other than we are, or take ourselves for; that our origins as human beings need accounting for, and are unaccountable. (418-419)

Questioning how far I will go to confirm the inside of the automaton in my subservience to the craftsman, Cavell continues his parable: as I have trained myself to think of the automaton as not having feelings but merely simulated "feelings," suppose that this time the craftsman snaps off $m y$ chest to reveal clockwork, showing that I am no different from the automaton (408) — then, do I have no feelings lying inside "feelings" like automata? Nay, "I certainly have.... But I do not mean it to preclude others from feeling it too. I just mean to assure myself that no one is in a better position to know what feeling abashed or feeling pain is than I am" (409). That is, in an epistemological construction that seeks grounds for being human inside, human beings are reduced exhaustively to simulatable shared knowledge; so, others are able to know all about me as well as I do myself, hence I become anonymous. It is in this premonition that the human horror arises, and then I am inclined to produce some "voice" in order to prove that I hold "authority" over myself. Thus, no matter how much knowledge about humans is clarified, there should remain the further problem that we actually speak it, i.e., that of how and when each of us uses that knowledge - our ways of "inhabiting that condition" (432). Possessing such a voice of our own is another human aspect of acknowledgment.

Cavell noted that when acknowledging another, "the moment at which I singled out my stranger was the moment at which I also singled out myself" (429). Indeed, in the above situation of vying for voice, we can find a reflexive structure in which the question of whether to acknowledge the other as a human being is also thrust upon oneself. This is because the way knowledge is used and developed is ultimately determined in a dyadic relationship between this particular "I" and "you" and, therefore, "acknowledgment of another calls for recognition of the other's specific relation to oneself" (428). (This is why at the end of the parable my interest shifted from the automaton to the craftsman and I raised my "voice" ("You've built in too much!").) The "other" to be acknowledged will then indicate not the other person, but rather "an other" (467) that forms a relationship between the two of us (Figure 1, left). This is nothing less than "separation" from the other mentioned in the previous section, in whose achievement "the necessary difference between being you and being me, the fact that we are two" (356) is opened. "Hence this is the focus at which the knowledge of oneself and of others meet" (459): my voice and your voice are discovered simultaneously in the form of their difference, involving both active and passive sides (352). "The soul is impersonal" (361), Cavell says in this sense.

This way of acknowledging others beyond the objectifying construction of Othering, 
thus, involves oneself as indivisible at a different level from Kumashiro's pedagogy of self-criticism. Although Cavell was criticized for narcissism by Kelz, he rather took others' absolute otherness so seriously that he became aware that it could not be known in any other form than that of difference from one's own

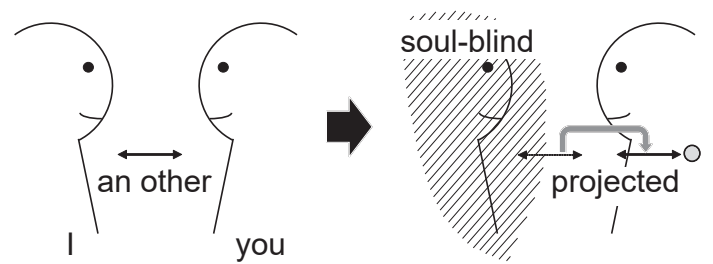

Figure 1 voice and, in this sense, had to turn his concern upon the self. If I forget this perspective of self-knowledge in knowing others, "I suffer a kind of blindness, but I avoid the issue by projecting this darkness upon the other" (368). A schematic explanation of this "soul-blindness" (378): if I am dark, as it were, the distance between me and the other whole is projected onto the connection between the other's body and mind, and acknowledgement becomes an epistemological matter of knowing the inner soul (Figure 1, right). No matter how much I trace this soul back to its origin, I fall into a kind of infinite regress, since the original distance between us can never be closed because of the necessary difference of our voices.

\section{Cavell's and Butler's Complementary Politics-The Case of Slavery}

The way of acknowledging others concurrent with discovering one's own voice has been revealed. This section considers its political implications, based on the example of slavery and its relation to acknowledgment as discussed by Cavell (1979).

In nineteenth-century America, the conflict had intensified between liberals appealing for the emancipation of slaves and conservatives justifying slavery against liberals' criticism. First, I quote a rather long remark on the Civil War that expresses Cavell's philosophical wish prominently:

[If] the justification for it was pushed to its final ground - that the slave is not a full human being - then that human misery represented an awful form of human progress; for that ground cannot in the long run be maintained. There are various reasons for regarding the American Civil War as a tragedy. One respectable reason would be to regard it as having been unnecessary, to suppose that slavery was becoming psychically insupportable on the part of the slaveowners. Now if it were shown that what was making the institution insupportable was not alone a sense of guilt...but an increasing effort to mean something that cannot be meant, producing a sense that the mind itself was about to overthrow itself; and if this psychic development were shown to have been proceeding with all deliberate speed, so that, left to itself, without being forced to self-justification in the face of sanctimonious criticism, it would have reached fruition and freed itself from slaveholding by Palm Sunday of 1865, then the Civil War was perhaps tragic because unnecessary, rather than tragic because necessary. (377)

Between liberals and conservatives there was a political argument about whether to see slaves as human beings. Butler (1999) would take the liberal position, considering her philosophical motive of saving those who are currently foreclosed from the human, hence from 
the living (cf. $x i x-x x)$. What Cavell insists here is that after slaveowners' justification has been exhausted, finally there is still a phase in which they acknowledge slaves' humanity, where they also discover their own humanity and realize, for the first time, what they have done.

While both Butler's and Cavell's focus would be on hearing slaves' voices, there is a divergence in attitude toward the same voices, and this can be understood by Cavell's (1979) contrast between eyes and ears (391). Eyes objectify voices, take them just as they see, or take their contents literally; Butlerian politics would, in response, aim to renew the norm so that slaves would be guaranteed human rights to life. Thus, it seems that voices have conventionally been assumed to be opinions that are represented and interpreted in the general form of information. In contrast, ears, which listen to others' voices in the true sense, pay attention to the significance of the primitive facts of actually uttering voices and vibrating the eardrum, which eyes fail to capture: from the fact that slaves speak, at least, somethinghave something to say, have voices - slaveowners acknowledge the existence of their minds, that they are human. This is the insight made possible by Cavell's career as a musician. ${ }^{7}$ This acknowledgement demands hearable distance, so is rooted in a specific dyadic relationship, in which our particular voices are discovered.

Thus, Cavell reminds us that no matter how much a diversity of voices is realized through Butler's politics, a certain human problem persists so long as the voices are conformist in the sense that they have not been discovered as our own and remain general. However, the complementary contribution that the particularity of voices can make to conventional politics will be abstracted when it is confused with a general meaning such as each individual's opinion. This paper, then, secures the sphere of particularity by calling it by the name of another politics: "the politics of voice."

It is true that the Cavellian voice, which is found in a dyadic conversation-hence after Butler's politics of interrogating the existing knowledge - within an intimate community with already shared knowledge, can be criticized for lacking a certain political urgency, as Kelz claims. ${ }^{8}$ However, if the perspective of the politics of voice is trivialized for this reason, even in a phase where the remaining problem may be slaveowners' acknowledgment of slaves, liberals would impatiently-because it proceeds "with all deliberate speed"-start insisting that the knowledge has not been interrogated enough. Here, the relationship between the particular "two" to be acknowledged (I and you) is generalized into a conflict between "two" political positions (we vs. they). In this construction of Othering, liberals could account for human grounds infinitely; so, if conservatives accordingly justify themselves against this, it will stir up further argumentative conflicts, having ultimately resulted in the Civil War (cf. 385). Cavell's wish is simply to avoid tragedies of this sort.

It is impossible in principle, however, to establish methodologically when and how to shift from Butler's politics to that of voice. This is because voices are dependent on particular situations. The politics of voice is a sphere "that cannot be meant" in that the attempt to stipulate what it is would be elusively caught up in the general language that writes conventional politics. ${ }^{9}$ In order to manage to illustrate that human beings do have an aspect of voice that cannot be described literally and, thereby, to create language to talk about it, Cavell's philosophy, unlike traditional forms, features an almost-too-repetitious employment of examples, as well as materials such as literature and movies. As such, it teaches us how to resist the poverty of imagination when thinking about politics. 


\section{Toward Education for the Politics of Voice}

This paper has discussed Butler's and Cavell's two forms of politics. In this process, I may have diminished the sharp critical impact that Butler's politics of interrogating shared knowledge should still have on, for example, the limitations of identity politics that continues to rely on the existing norm: this is because I have depicted it formulaically with its reductive classification into the analytic framework of generality. This sacrifice, however, revealed contrastively the existence of the complementary sphere of Cavell's politics of voice in which to acknowledge our particular ways of inhabiting lives constituted by common knowledge.

While both politics advocate overcoming the epistemology of knowing others, they present no alternative to knowledge itself. Human beings, after all, are given no means except the medium of knowledge to understand each other. What they set out to do in two different ways is to address the finitude of knowledge. In conclusion, then, I want to show their respective prospects for political education. Butler's politics evokes the finitude of the knowledge of others on which we currently rely and opens it to infinite possibilities. Here education will be to learn the practice of the deconstructive repetition of language to resist the norm from within. In contrast, the politics of voice, which acknowledges the other in the form of finding out that I and the other are absolutely different, accepts epistemic finitude itself instead of sending it back to infinity. Here education will be to foster engagement with language to perceive the psychological passage at that moment. Its methodology cannot be described generally because of the particularity of voice, but probably learned from Cavell's way of encountering Shakespearean drama, Blake's poems, and Hollywood movies, which is neither to draw a general lesson, comprehend their content in summary, nor interpret the characters' minds.

\section{Notes}

1 Analyzing Cavell's vision of language in terms of gender, Viefhues-Bailey (2007) shows that "[h]e is keenly aware that it is incorrect to see language as a commodity that...is in principle equally accessible to everyone regardless of gender, race, or social location" (3).

2 For concrete examples, see, for instance, Excitable Speech (Butler 1997).

3 Yamaguchi (2016) also poses the task of overcoming the divide between the political spheres in Butler (206).

4 While the capitalization of the "Other" is by Levinas, that of "Othering" is by Kumashiro, and there is no direct connection between them. This coincidence, however, seems effective because this paper shows that Levinas's "Other" remains, after all, within the epistemological construction of "Othering."

5 Standish (2007) finds a positive educational significance with Cavell's persistence in concreteness in the comparison between the finite other in Cavell and the infinite Other in Levinas (87-89).

6 Originally published in Japanese. In translating this into English, I referred to Saito $(2005,172)$.

7 For Cavell's autobiographical discussion on the relation between his musical career and the concept of voice, see A Pitch of Philosophy (1994, especially chapter 1).

8 Saito (2015) insists that understanding other cultures necessitates destabilizing one's own framework of thinking in terms of "translation"-an idea drawn from Cavell's philosophy. Translation is not simply "a mechanical process of switching from one language to another" but has an existential significance that "involves the encountering of the strange in the familiar"- - native language and native culture - through reengagement with language, "where one finds anew one's place in one's language and culture" (22). This form of "finding one's voice" (24) differs (in 
phase) from acknowledgment, in which one's voice is found in the form of its difference from the other's voice. Rather, it should be shared with Butler's politics, considering that translation is "rediscovering culture's resourcefulness," or rediscovering that "sources are constantly being renewed... and sensitization of this opens a path for critical thinking" (ibid.). Saito, however, drawing on Cavell's theory of literature (on Thoreau's Walden) - The Senses of Walden (1981)-delineates a self's linguistic experience vividly and dramatically in contrast to Butler, who discusses the functional side of language, relying on Derrida (cf. Standish 2007, 77). In this sense, Saito sheds light on an educational aspect of self-transformation in Cavell's philosophy, which is something that Kelz overlooks in criticizing him by comparison with Butler.

9 Since Butler's focus, for example in her main work Gender Trouble (1999), lies in opening up the possibilities of gender categories by challenging them from within their constitution, rather than defining new categorizations (cf. vii-viii), it is contradictory that she sometimes makes typical declarations such as "there is no reason to assume that genders ought...to remain as two" (10), which can invite an incorrect reception of her thought. Considering she says she describes the book autobiographically as "I" who has experienced violence surrounding sexuality, this inconsistency can be interpreted as an expression of the distortion arising from the necessary subjection to the norm to become a subject (indeed, she argues that she makes this complicated style itself convey the difficulty about the subject (xxv-xxvi)). However, since "I" should indicate the particular self rather than a general subject, it might be possible to relocate this distortion in a Cavellian system as a trace of her own "voice" calling for acknowledgment that "cannot be meant" and is caught up in general language. Due to the limited space, this problem of the gasping of voice in Butler cannot be given full attention here.

\section{References}

Butler, J. (1997). Excitable speech: A politics of the performative. New York: Routledge.

Butler, J. (1999). Gender trouble: Feminism and the subversion of identity (10th anniversary ed.). New York: Routledge.

Cavell, S. (1979). The claim of reason: Wittgenstein, skepticism, morality, and tragedy. Oxford: Oxford University Press.

Cavell, S. (1981). The senses of Walden (Expanded ed.). San Francisco: North Point Press.

Cavell, S. (1994). A pitch of philosophy: Autobiographical exercises. Cambridge: Harvard University Press.

Cavell, S. (1998). Nichijosei eno kaiki: Watashi no koe, America no koe [Return to the ordinary: My voice and America's voice]. (Interviewed and translated by N. Saito). Gendai Shiso [Contemporary Thoughts], 26(1), 50-59. (Japanese)

Cavell, S. (2005a). Philosophy the day after tomorrow. Cambridge: The Belknap Press of Harvard University Press.

Cavell, S. (2005b). Responses. In R. B. Goodman (Ed.), Contending with Stanley Cavell (pp. 157176). Oxford: Oxford University Press.

Kelz, R. (2016). The non-sovereign self, responsibility, and otherness: Hannah Arendt, Judith Butler, and Stanley Cavell on moral philosophy and political agency. Basingstoke: Palgrave Macmillan.

Kumashiro, K. K. (2002). Troubling education: Queer activism and antioppressive pedagogy. New York: RoutledgeFalmer.

Matsuoka, Y. (2000). Minority. In Kyoiku Shisoshi Gakkai (Ed.), Kyoiku shiso jiten [Dictionary of educational thought] (pp. 654-656). Tokyo: Keiso Shobo. (Japanese)

Saito, N. (2005). The gleam of light: Moral perfectionism and education in Dewey and Emerson. New York: Fordham University Press.

Saito, N. (2015). Philosophy as translation and understanding other cultures: Becoming a global citizen through higher education. Educational Studies in Japan, 9, 17-26.

Standish, P. (2007). Education for grown-ups, a religion for adults: Scepticism and alterity in Cavell and Levinas. Ethics and Education, 2(1), 73-91.

Viefhues-Bailey, L. H. (2007). Beyond the philosopher's fear: A Cavellian reading of gender, origin 
and religion in modern skepticism. Farnham: Ashgate.

Yamaguchi, K. (2016). J. Butler niokeru "seiji kyoiku" [Butler's political education]. Bulletin of the Division of Basic Theories of Education, Graduate School of Education, the University of Tokyo, 42, 205-214. (Japanese) 